\title{
Epidemiological profile of invasive bacterial diseases in children in Casablanca, Morocco: antimicrobial susceptibilities and serotype distribution
}

\author{
N. ElMdaghri, ${ }^{7}$ N. Jilali, ${ }^{2}$ H. Belabbes, ${ }^{1}$ Z. Jouhadi, ${ }^{2}$ M. Lahssoune ${ }^{7}$ and S. Zaid ${ }^{7}$
}

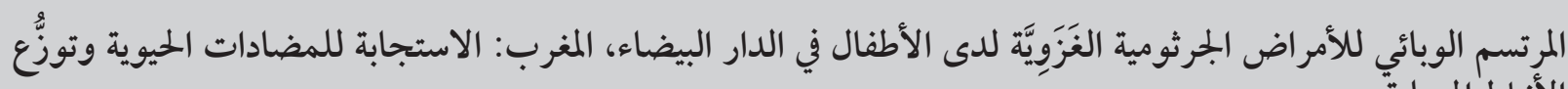

$$
\begin{aligned}
& \text { الأنجاط المصلية } \\
& \text { نعيمة المدغري، نجيب جيلالي، حورية بلعبّاس، زينب جهادي، منى لحسون، سميرة زيد }
\end{aligned}
$$

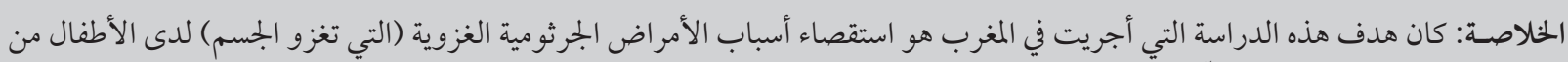

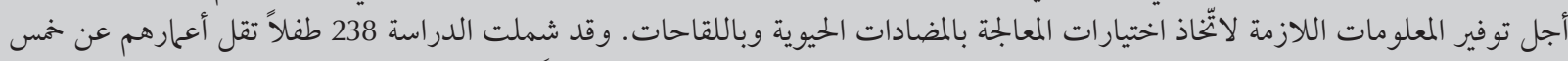

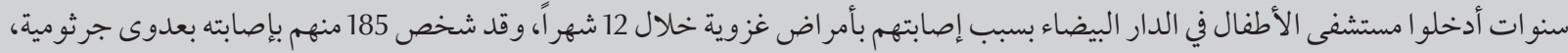

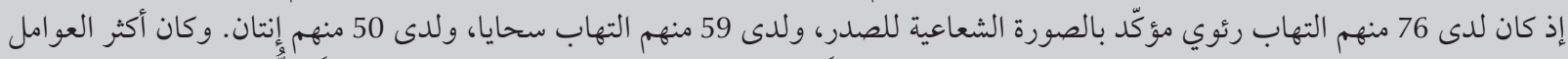

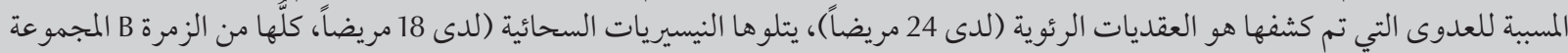

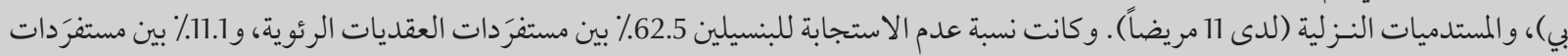

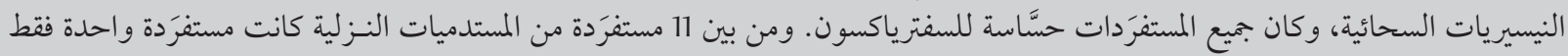

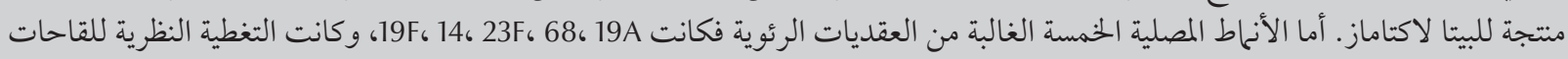

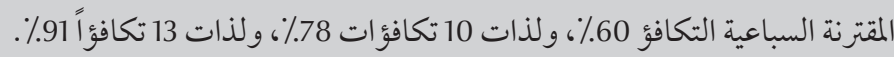

ABSTRACT The aim of this prospective study in Morocco was to investigate the causes of invasive bacterial diseases in children in order to inform antibiotic therapy and vaccine choices. Of 238 children aged $\leq 5$ years admitted to the Children's Hospital of Casablanca for invasive diseases over a 12-month period, 185 were diagnosed with bacterial infection: 76 had chest-X-ray-confirmed pneumonia, 59 had meningitis and 50 had sepsis. Streptococcus pneumoniae was the most common pathogen identified $(n=24)$, followed by Neisseria meningitidis ( $n=18$, all group B) and Haemophilus influenzae $(n=11)$. The rate of penicillin non-susceptibility was $62.5 \%$ among Str. pneumoniae isolates and $11.1 \%$ among $N$. meningitidis and all isolates were ceftriaxone-susceptible. Of the $11 \mathrm{H}$. influenzae isolates, only 1 produced a beta-lactamase. The 5 predominant Str. pneumoniae serotypes were 19F, 14, 23F, 6B and 19A and the theoretical coverage of the 7,10 and 13 -valent pneumococcal conjugate vaccines was $60 \%, 78 \%$ and $91 \%$ respectively.

Profil épidémiologique des maladies bactériennes invasives chez des enfants à Casablanca (Maroc) : sensibilités antimicrobiennes et distribution des sérotypes

RÉSUMÉ La présente étude prospective menée au Maroc visait à rechercher les causes des maladies bactériennes invasives chez des enfants permettant d'orienter le choix des traitements antibiotiques et des vaccins. Sur 238 enfants âgés de 5 ans ou moins admis à l'Hôpital des enfants de Casablanca pour des maladies invasives sur une période de 12 mois, 185 ont reçu le diagnostic d'infection bactérienne : 76 souffraient de pneumonie confirmée par une radiographie des poumons, 59 étaient atteints d'une méningite et 50 de septicémie. Streptococcus pneumoniae était l'agent pathogène le plus fréquemment identifié $(n=24)$, suivi par Neisseria meningitidis ( $n=18$, ensemble du groupe B) puis par Haemophilus influenzae $(n=11)$. Le taux de non-sensibilité à la pénicilline était de $62,5 \%$ pour les isolats de Str. pneumoniae et de 11,1\% pour les isolats de N. meningitidis alors que tous les isolats étaient sensibles à la ceftriaxone. Sur les 11 isolats d'H. influenzae, un seul produisait une bêta-lactamase. Les cinq sérotypes prédominants de Str. pneumoniae étaient 19F, 14, 23F, 6B et 19A et la couverture théorique des vaccins antipneumococciques conjugués à 7, 10 et 13 valences était de $60 \%, 78$ \% et $91 \%$ respectivement.

${ }^{1}$ Department of Microbiology; ${ }^{2}$ Department of Infectious Diseases, Children's Hospital, Ibn Roch Centre University Hospital, Faculty of Medicine and Pharmacy, Casablanca, Morocco (Correspondence to N. El Mdaghri: naimaelmdaghri@yahoo.fr).

Received: 08/07/11; accepted: 11/01/12 


\section{Introduction}

Streptococcus pneumoniae, Haemophilus influenzae and Neisseriameningitidisinfections are important cause of morbidity and mortality in children worldwide [1]. Strategies for prevention of the diseases and the deaths and the complications that they cause include good case management with appropriate antibiotic therapy and immunization against the predominant serotypes. Given the regular increase of antibiotic resistance to Str. pneumoniae over the last 3 decades, with marked geographic variations [2], it is important to have current, local data on the pattern of drug resistance in order to formulate appropriate recommendations for therapy. Furthermore, given the geographical and temporal variation of serotype distribution of $N$. meningitidis and Str. pneumoniae, reliable epidemiological data are required to support evidence-based decision-making for the introduction of new vaccines to national immunization programmes.

To address this need, the World Health Organization (WHO) has developed a global framework for immunization monitoring and surveillance which outlines the need for surveillance of the vaccine-preventable diseases [3]. The WHO Regional Office for the Eastern Mediterranean (EMRO) coordinates the Vaccine-Preventable Invasive Bacterial Diseases Surveillance Network, which is based on sentinel surveillance and is still ongoing, to help provide data that would inform vaccine introduction decisions $[4,5]$. The Ibn Rochd University Hospital Centre at the Children's Hospital of Casablanca participated as the only sentinel site in Morocco for meningitis, pneumonia and sepsis surveillance, in order to generate supplementary data on the epidemiological profile of causative pathogens of invasive bacterial diseases among hospitalized children aged under 5 years. In this study we report on the results of this 1-year laboratorybased surveillance.

\section{Methods}

The study was conducted between September 2007 and August 2008 at the Ibn Roch Centre University Hospital in Casablanca, Morocco. All children aged $\leq 5$ years hospitalized in the Children's Hospital who met the WHO criteria of case definition of meningitis, chest-X-ray-(CXR)-confirmed pneumonia or sepsis [6] were included . Blood, cerebrospinal fluid (CSF) and pleural fluid, if indicated, were collected as part of the routine clinical practice of patient care according to standardized operating procedures, and were processed in the microbiology laboratory following standard bacteriological methods [7].

For all CSF samples, appearance, white blood cells count, Gram stain, culture on supplemented chocolate agar and Mueller-Hintonagarplus 5\% sheep blood (MHS kit, bioMérieux) and latex agglutination test (Slidex meningite kit 5, bioMérieux) were performed. Blood cultures were incubated and monitored in the BACTEC 9000 automated system (Becton Dickinson). The primary organisms of interest were identified by recommended techniques: morphology on Gram stain, alpha haemolysis, optochin and bile solubility tests for Str. pneumoniae, oxidase and carbohydrate utilization test (API NH, bioMérieux) for N. meningitidis and X \& V factor test for H. influenzae.

Antibiotic susceptibility testing was done following Clinical Laboratory Standard Institute (CLSI) guidelines [8] on Mueller-Hinton agar supplemented with 5\% sheep blood (bioMérieux) for Str. pneumoniae and N. meningitidis and on haemophilus test medium (Oxoid) for H. influenzae. Resistance of strains to erythromycin, chloramphenicol, trimethoprim/sulfamethoxazole and rifampicin were tested by the disk diffusion method (BioRad). Minimal inhibitory concentrations (MIC) for penicillin G, amoxicillin/ampicillin and ceftriaxone were determined by E-tests (AB Biodisk). $H$. influenzae beta-lactamase detection was performed with nitrocefin-impregnated disks (Cefinase, Becton-Dickinson).

Routine internal quality control was performed by testing the American Type Culture Collection (ATCC) strains of Str. pneumoniae (ATCC 49619), Escherichia coli (ATCC 25922) and H. influenzae (ATCC 49247). The cutoffs used for interpretation were those recommended by the CLSI in 2005.

Serotyping of $H$. influenzae and $N$. meningitidis were performed by latex agglutination (Slidex meningitis kit, bioMérieux). Str. pneumoniae isolates were serotyped by latex agglutination and capsular swelling procedure (Quellung reaction) with latex and type specific antipneumococcal pool, group or type and factor sera (Staten Serum Institute).

\section{Data analysis}

The data were entered into a Microsoft Access database developed by the data management coordinator of Vaccine Preventable Diseases and Immunization (VPI) at WHO-EMRO and then analysed by Epi Info, version 6.02.

\section{Results}

From September 2007 to August 2008, 238 children aged $\leq 5$ years with clinical symptoms of invasive diseases were hospitalized at the Children's Hospital. Of them 185 were diagnosed with bacterial invasive infection, tuberculosis excluded: 76 with CXR-confirmed pneumonia, 59 with meningitis and 50 with sepsis, according to $\mathrm{WHO}$ case definitions.

\section{Causative organisms}

The main causative organisms identified were Str. pneumoniae $(n=24), N$. meningitidis $(n=18)$ and $H$. influenzae $(n=11)$. In 31 out of the $59(52.5 \%)$ cases of meningitis, CSF and/or blood 


\begin{tabular}{|c|c|c|c|c|c|c|c|c|c|}
\hline \multirow[t]{3}{*}{ Diagnosis } & \multirow{3}{*}{$\begin{array}{l}\text { Total } \\
\text { No. }\end{array}$} & \multirow{2}{*}{\multicolumn{2}{|c|}{$\begin{array}{l}\text { At least } 1 \text { specimen } \\
\text { positive }\end{array}$}} & \multicolumn{3}{|c|}{ Age groups (years) } & \multicolumn{3}{|c|}{ Specimen source } \\
\hline & & & & \multirow{2}{*}{$\begin{array}{l}0-1 \\
\text { No. }\end{array}$} & \multirow{2}{*}{$\begin{array}{l}1-2 \\
\text { No. }\end{array}$} & \multirow{2}{*}{$\begin{array}{l}2-5 \\
\text { No. }\end{array}$} & \multirow{2}{*}{$\begin{array}{l}\text { CSF } \\
\text { No. }\end{array}$} & \multirow{2}{*}{$\begin{array}{l}\text { Blood } \\
\text { No. }\end{array}$} & \multirow{2}{*}{$\begin{array}{c}\text { Pleural fluid } \\
\text { No. }\end{array}$} \\
\hline & & No. & $\%$ & & & & & & \\
\hline All probable/definite meningitis & 59 & 31 & 52.5 & 29 & 10 & 20 & 29 & 16 & - \\
\hline Streptococcus pneumoniae & 11 & 11 & & 10 & 1 & 0 & 10 & 7 & - \\
\hline Neisseria meningitidis ${ }^{\mathrm{a}}$ & 14 & 14 & & 3 & 3 & 8 & 13 & 4 & - \\
\hline Haemophilus influenzae type B & 6 & 6 & & 3 & 2 & 1 & 6 & 5 & - \\
\hline CXR-confirmed pneumonia & 76 & 11 & 14.5 & 23 & 24 & 29 & - & 10 & 3 \\
\hline Str. pneumoniae & 8 & 8 & & 5 & 2 & 1 & - & 7 & 2 \\
\hline H. influenzae & 2 & 2 & & 2 & 0 & 0 & - & 2 & 0 \\
\hline Staphylococcus aureus & 1 & 1 & & 1 & 0 & 0 & - & 1 & 1 \\
\hline Septicaemia/sepsis & 50 & 18 & 36.0 & 26 & 15 & 9 & 0 & 18 & 0 \\
\hline Str. pneumoniae & 5 & 5 & & 2 & 3 & 0 & 0 & 5 & 0 \\
\hline N. meningitidis ${ }^{\mathrm{a}}$ & 4 & 4 & & 1 & 3 & 0 & 0 & 4 & 0 \\
\hline H. influenzae & 3 & 3 & & 1 & 2 & 0 & 0 & 3 & 0 \\
\hline Other $^{b}$ & 6 & 6 & & 5 & 1 & 0 & 0 & 6 & 0 \\
\hline Total identified organisms & 60 & 60 & 32.4 & 33 & 17 & 10 & 29 & 44 & 3 \\
\hline
\end{tabular}

${ }^{a}$ All group $B ;{ }^{b}$ Other $=$ Escherichia coli $(n=3)$, Streptococcus pyogenes $(n=1)$, Salmonella typhimurium $(n=1)$, Shigella flexneri $(n=1)$.

$C X R=$ chest $X$-ray; $C S F=$ cerebrospinal fluid.

culture results confirmed the etiology (Table 1). N. meningitidis was the most frequently identified organism in meningitis $(n=14)$, followed by Str. pneumoniae $(n=11)$ and $H$. influenzae $(n=6)$. Of the 11 cases of pneumococcal meningitis, 10 (90.9\%) occurred among children aged $<12$ months. Laboratory results confirmed the etiology in $11(14.5 \%)$ cases of CXR-confirmed pneumonia by blood and/or pleural fluid culture and in $18(36 \%)$ cases of sepsis. During the study period 4 deaths occurred: 3 cases of meningitis (2 Str. pneumoniae and $1 \mathrm{H}$. influenzae) and 1 case of meningococcaemia.

\section{Antibiotic susceptibility}

All the 24 Str. pneumoniae isolates were susceptible to ceftriaxone and 15 (62.5\%) were penicillin non-susceptible with an MIC $\geq 2 \mu \mathrm{g} / \mathrm{mL}$ in 2 cases (Table 2). The rates of non-susceptibility to amoxicillin, erythromycin and trimethoprim-sulfamethoxazole were $4.2 \%$, $16.6 \%$ and $33.3 \%$ respectively. All the $18 \mathrm{~N}$. meningitidis isolates were susceptible to ampicillin, ceftriaxone, chloramphenicol and rifampicin, and 2 (11.1\%) were penicillin non-susceptible (MICs $=0.12$ and $0.25 \mu \mathrm{g} / \mathrm{mL}$ ). Only $10 / 11$ $H$. influenzae isolates were tested for antibiotic susceptibility ( 1 case was confirmed by latex agglutination on CSF). Of the $10 \mathrm{H}$. influenzae isolates tested, only 1 produced a beta-lactamase and was ampicillin non-susceptible (MIC $=4 \mathrm{mg} / \mathrm{L}$ ).

\section{Serotyping}

Among the 23 Str. pneumoniae isolates serotyped 9 different serotypes were recognized; serotype 19F (17.4\%) was the most frequent, followed by serotypes $23 \mathrm{~F}, 14,6 \mathrm{~B}$ and 19A (13.0\% each). The other pneumococcal serotypes found were 1 (8.7\%), 3, 5 and $18 \mathrm{C}$ ( $4.3 \%$ each) and 2 pneumococcal isolates $(8.7 \%)$ were non-vaccine serotypes. Of the 23 Str. pneumoniae isolates serotyped, 14 (60.9\%), 17 (73.9\%) and $21(91.3 \%)$ were included in the 7,10 or 13-valent pneumococcal conjugate vaccine (PCV) respectively. All of the $18 \mathrm{~N}$. meningitidis isolates belonged to group B. Of the $11 \mathrm{H}$. influenzae isolates 10 were of serotype $B$ and 1 was noncapsulated.

\section{Discussion}

During this 1-year study in Morocco H. influenzae was responsible for only 11 cases of invasive diseases among hospitalized children. In past years this bacteria was ranked first among the causative agents of invasive diseases in childhood with about 70 cases/year [9]. The results therefore suggest that in 2008, only a few months after the introduction of the H. influenzae type B ( $\mathrm{Hib}$ ) vaccine into the national programme of immunization, there may have been a change in the epidemiological profile of invasive infections in childhood, similar to what has occurred in several industrialized countries [10]. In our study $N$. meningitidis was the most common agent of bacterial meningitis in children (14/59, 23.7\%), particularly those over 1 year old, while Str. pneumoniae ranked first in young infants during the first months of life ( $90.9 \%<12$ months). If we consider all invasive infections studied, Str. pneumoniae was the most common pathogen in childhood. This trend was observed in the 1990s in industrialized countries after the 


\begin{tabular}{|c|c|c|c|c|c|c|}
\hline \multirow[t]{3}{*}{ Antibiotic } & \multicolumn{6}{|c|}{ Non-susceptible isolates } \\
\hline & \multicolumn{2}{|c|}{$\begin{array}{c}\text { Str. pneumoniae } \\
(n=24)\end{array}$} & \multicolumn{2}{|c|}{$\begin{array}{l}\text { N. meningitides } \\
(n=18)\end{array}$} & \multicolumn{2}{|c|}{$\begin{array}{l}\text { H. influenzae } \\
(n=10)\end{array}$} \\
\hline & No. & $\%$ & No. & $\%$ & No. & $\%$ \\
\hline Beta lactamase +ve & - & - & - & - & 1 & 10.0 \\
\hline Penicillin, $0.12 \mathrm{mg} / \mathrm{L} \leq \mathrm{MIC} \leq 1 \mathrm{mg} / \mathrm{L}$ & 13 & 54.2 & 2 & 11.1 & - & - \\
\hline Penicillin, MIC $\geq 2 \mathrm{mg} / \mathrm{L}$ & 2 & 8.3 & 0 & 0.0 & - & - \\
\hline Amoxicillin, MIC $\geq 0.5 \mathrm{mg} / \mathrm{L}$ & 1 & 4.2 & 0 & 0.0 & - & - \\
\hline Amoxicillin, MIC $\geq 2 \mathrm{mg} / \mathrm{L}$ & - & - & - & - & 1 & 10.0 \\
\hline Ceftriaxone, $\mathrm{MIC} \geq 0.5 \mathrm{mg} / \mathrm{L}$ & 0 & 0.0 & 0 & 0.0 & 0 & 0.0 \\
\hline Erythromycin & 4 & 16.6 & - & - & - & - \\
\hline Chloramphenicol & 0 & 0.0 & 0 & 0.0 & 0 & 0.0 \\
\hline Trimethoprim-sulfamethoxazole & 8 & 33.3 & 13 & 72.2 & 1 & 10.0 \\
\hline Rifampicin & - & - & 0 & 0.0 & 0 & 0.0 \\
\hline
\end{tabular}

Clinical Laboratory Standard Institute 2005 criteria [8].

MIC = minimum inhibitory concentration; - = not applicable (Str. pneumoniae) or not tested (N. meningitidis).

introduction of the Hib vaccine, which resulted in a more than $98 \%$ decrease in the incidence of $H$. influenzae invasive disease [11] and the development of pneumococci as a cause of paediatric invasive diseases. Furthermore, in our study pneumococcal meningitis had a worse prognosis with a high case fatality rate (18.2\%) and, despite the small size of the sample, the rate of penicillin nonsusceptibility among paediatric invasive isolates was alarming (62.5\%).

In Casablanca the surveillance of antibiotic resistance in Str. pneumoniae started in 1994 and showed a relatively favourable situation with about $10 \%$ of Str. pneumoniae penicillin-resistant [12]. Penicillin non-susceptibility rates increased significantly over the 4-year period 2006-08, particularly among paediatric isolates $[13,14]$. The rate of penicillin non-susceptibility observed in our study is comparable with that observed in the Mediterranean region $[15,16]$. Antibiotic resistance may be enhanced by the excessive availability or inappropriate use of antibiotics in these countries, especially due to self-treatment with readily available over-the-counter antibiotics. On the other hand, 16 (72.7\%) of 23 Str. pneumoniae serotypes isolates belonged to 5 serotypes (19F, 23F, 14, 6B and 19A). This is the first time that a Moroccan study described the serotype distribution of Str. pneumoniae responsible for invasive infections in children $\leq 5$ years and reported a major role for serotype 19 A which ranked 2 nd along with serotypes $6 \mathrm{~B}, 14$ and $23 \mathrm{~F}$ (found in $>13 \%$ of the isolates). Thus the theoretical coverage of the 3 available PCV was $60.1 \%$ for the 7 -valent, $78.3 \%$ for the 10 -valent and $91.3 \%$ for the 13 -valent. Comparable data have been reported in several industrialized countries in the years 2000, when the PCV-7 had just become available and was being introduced into vaccine schedules [17]. Its widespread used led to substantial reductions in the incidence of invasive pneumococcal disease by direct and herd effects, despite the serotype replacement reported [2].

Most of the penicillinnon-susceptible isolates were identified among vaccine serotypes, suggesting that vaccine introduction might substantially reduce the developing of pneumococcal antibiotic resistance. In sub-Saharan Africa, where pneumococcal antibiotic resistance levels were relatively low, serotype coverage of PCV-7 was also relatively low [18]. In the East African region, the potential coverage of PCV-10 was estimated as $\geq 80 \%$
[17] and, in a recent Tunisian study, the calculated potential coverage of PCV-7 was $62.8 \%$ for paediatric invasive pneumococcal isolates [14].

There are large geographic and temporal variations in the epidemiologic profile of meningococcal diseases. This study confirms what was previously reported by Zerouali et al. [19]. In Morocco, serogroup B predominated in paediatric infections and the rate of penicillin decreased-susceptibility (MICs $\geq$ $0.06 \mu \mathrm{g} / \mathrm{mL}$ ) was still low, in contrast to reports from in several countries of rates up to $38 \%$ [20-22]. Thus, since no broadly effective vaccine is available for diseases caused by serogroups B [23], no prevention programme based on vaccination can be adopted.

\section{Conclusions}

The results of this study show that Morocco made the right choice with the implementation of new vaccines. However, efforts are still needed to control the increase in antibiotic resistance by adopting a policy for prudent antibiotic use. Continued surveillance is important to detect any changes and for the development of guidelines for therapy and prophylaxis. 
Acknowledgements

This study was supported by grants from the World Health Organization, Regional
Office for the Eastern Mediterranean (projects TSA 07/20 and TSA 07/21).

We would like to thank Dr Nadia Teleb, Epidemiological Surveillance
Officer and Mr Hossam El-Ashmony Data Management Coordinator, Vaccine Preventable Diseases and Immunization, WHO-EMRO.

\section{References}

1. Kaijalainen T et al. Invasive infections caused by Neisseria meningitidis, Haemophilus influenzae and Streptococcus pneumoniae among children in St Petersburg, Russia. Clinical Microbiology and Infection, 2008, 14:507-510.

2. Linares J et al. Changes in antimicrobial resistance, serotypes and genotypes in Streptococcus pneumoniae over a 30-year period. Clinical Microbiology and Infection, 2010, 16(5):402-410.

3. Global framework for immunization monitoring and surveillance, Geneva, World Health Organization, 2007

4. Global meeting on surveillance invasive bacterial vaccine preventable diseases (IB-VPD) and rotavirus-action plan for the period of September 2010 to September 2011. Geneva, World Health Organization, 2010.

5. Global Invasive Bacterial Vaccine Preventable Diseases (IB-VPD) information and surveillance bulletin. Reporting period January through December 2009. Volume 2, July 2010. Geneva, World Health Organization, 2010.

6. WHO-recommended standards for surveillance of selected-vaccine preventable diseases. Geneva, World Health Organization, 2003 (WHO/V\&B/03.01).

7. Vandepitte J et al. Basic laboratory procedures in clinical bacteriology, 2nd ed. Geneva, World Health Organization, 2003.

8. Clinical Laboratory Standard Institute guidelines. Performance standards for antimicrobial disk susceptibility testing. Approved standards M100-S14, 15th ed. Wayne, Pennsylvania, Clinical and Laboratory Standards Institute, 2005.

9. Moustaoui $\mathrm{N}$ et al. Serotypes, biotypes and antimicrobial susceptibility of Haemophilus influenzae from invasive disease in Casablanca. Clinical Microbiology and Infection, 1999, 21:627-632.

10. Sarlangue J, Levy C, Cohen R. Epidémiologie des méningites bactériennes de l'enfant en France [Epidemiology of bacterial meningitis in children in France]. Archives de Pédiatrie, 2006, 13:569-571.

11. Dworkin MS, Park L, Borchardt SM. The changing epidemiology of invasive Haemophilus influenzae disease, especially in persons > or $=65$ years old. Clinical Infectious Diseases, 2007, 44:810-816.

12. Belabbes $\mathrm{H}$ et al. Sérotypes et sensibilité aux antibiotiques des Streptococcus pneumoniae isolés au CHU de Casablanca entre 1994 et 1997 [Serotypes and antibiotic susceptibility of Streptococcus pneumoniae isolated in Casablanca University Hospital between 1994 and 1997]. Maroc Médical, 2001, 224:265-271.
13. El Mdaghri $\mathrm{N}$ et al. Changing epidemiology of Streptococcus pneumoniae in Morocco, 2006-2008: implications for national immunization program. Abstract number: P2018. 20th European Congress of Clinical Microbiology and Infectious Diseases, Vienna, Austria, 10-13 April, 2010.

14. Benbachir $\mathrm{M}$ et al. Eleven-year surveillance of antibiotic resise tance in Streptococcus pneumoniae in Casablanca (Morocco). Microbial Drug Resistance, 2012, 18(2):157-160.

15. Smaoui $\mathrm{H}$ et al. Sensibilité aux antibiotiques et distribution des sérotypes des souches de Streptococcus pneumoniae isolées chez l'enfant à Tunis [Antibiotic susceptibility and serotype distribution of Streptococcus pneumoniae strains isolated from children in Tunis]. Archives de Pédiatrie, 2009, 16:220-226.

16. Borg MA et al. Prevalence of penicillin and erythromycin resistance among invasive Streptococcus pneumoniae isolates reported by laboratories in the southern and eastern Mediterranean region. Clinical Microbiology and Infection, 2009, 15:232-237.

17. Advisory Committee of Immunization Practices. Preventing pneumococcal disease among infants and young children. Recommendations of the Advisory Committee of Immunization Practices (ACIP). Morbidity and Mortality Weekly Report, 2000, 49:RR-9.

18. Mudhune S, Wamae M. Report on invasive disease and meningitis due to Haemophilus influenzae and Streptococcus pneumonia from the Network for Surveillance of Pneumococcal Disease in the East African Region. Clinical Infectious Diseases, 2009, 48:S147-S152.

19. Zerouali $\mathrm{K}$ et al. Serogroups, serotypes, serosubtypes and antimicrobial susceptibility of Neisseria meningitidis isolates in Casablanca. European Journal of Clinical Microbiology \& Infectious Diseases, 2002, 21:483-485.

20. Mignon Du Pleissis M et al. Neisseria meningitidis intermediately resistant to penicillin and causing invasive disease in South Africa in 2001 to 2005. Journal of Clinical Microbiology, 2008, 46:3208-3214.

21. Brown S, Riley G. Neisseria meningitidis with decreased susceptibility to penicillin in Ontario. Canada Communicable Disease Report, 2001, 27:73-75.

22. Ferreira E, Canica M. Invasive meningococci with reduced susceptibility to penicillin in Portugal. Journal of Antimicrobial Chemotherapy, 2002, 49:424-425.

23. Poland GA. Prevention of meningococcal diseases: current use of polysaccharide conjugate vaccines. Clinical Infectious Diseases, 2010, 50:S43-S53. 